\title{
Article \\ Blood-Brain Barrier Dynamic Device with Uniform Shear Stress Distribution for Microscopy and Permeability Measurements
}

\author{
Nina Choublier ${ }^{1, *}$, Yoann Müller ${ }^{2}$, Loris Gomez Baisac ${ }^{2}$, Jeremy Laedermann ${ }^{2}$, Casimir de Rham ${ }^{2}$, \\ Xavier Declèves 1,3 and Adrien Roux ${ }^{2, *(D)}$ \\ 1 INSERM, UMR S-1144 Therapeutic Optimisation in Neuropsychopharmacology, University of Paris, \\ F-75006 Paris, France; xavier.decleves@parisdescartes.fr \\ 2 Tissue Engineering Laboratory, HEPIA HES-SO, University of Applied Sciences and Arts Western \\ Switzerland, CH-1202 Geneva, Switzerland; yoann.muller@bluewin.ch (Y.M.); \\ loris.gomez-baisac@hesge.ch (L.G.B.); jeremy.laedermann@gmail.com (J.L.); derhamc@bluewin.ch (C.d.R.) \\ 3 Biologie du Médicament, AP-HP, Hôpital Cochin, 27 Rue du Faubourg St. Jacques, CEDEX 1, \\ F-75679 Paris, France \\ * Correspondence: nina.choublier@hotmail.fr (N.C.); adrien.roux@hesge.ch (A.R.)
}

\section{check for} updates

Citation: Choublier, N.; Müller, Y.; Gomez Baisac, L.; Laedermann, J.; de Rham, C.; Declèves, X.; Roux, A. Blood-Brain Barrier Dynamic Device with Uniform Shear Stress

Distribution for Microscopy and Permeability Measurements. Appl. Sci. 2021, 11, 5584. https://doi.org/ 10.3390/app11125584

Academic Editors: Matteo Agostini and Marco Cecchini

Received: 20 April 2021

Accepted: 15 June 2021

Published: 16 June 2021

Publisher's Note: MDPI stays neutral with regard to jurisdictional claims in published maps and institutional affiliations.

Copyright: (c) 2021 by the authors. Licensee MDPI, Basel, Switzerland. This article is an open access article distributed under the terms and conditions of the Creative Commons Attribution (CC BY) license (https:/ / creativecommons.org/licenses/by/ $4.0 /)$.

\begin{abstract}
Neurology has always been one of the therapeutic areas with higher attrition rates. One of the main difficulties is the presence of the blood-brain barrier (BBB) that restricts access to the brain for major drugs. This low success rate has led to an increasing demand for in vitro tools. The shear stress, which positively affects endothelial cell differentiation by mimicking blood flow, is required for a more physiological in vitro BBB model. We created an innovative device specifically designed for cell culture under shear stress to investigate drug permeability. Our dynamic device encompasses two compartments communicating together via a semi-permeable membrane, on which human cerebral microvascular endothelial (hCMEC/D3) cells were seeded. The fluidic controlled environment ensures a laminar and homogenous flow to culture cells for at least seven days. Cell differentiation was characterized by immunodetection of inter-endothelial junctions directly in the device by confocal microscopy. Finally, we performed permeability assay with lucifer yellow in both static and dynamic conditions in parallel. Our dynamic device is suited to the evaluation of barrier function and the study of drug transport across the BBB, but it could also be used with other human cell types to reproduce intestinal or kidney barriers.
\end{abstract}

Keywords: blood-brain barrier; brain endothelial cell; shear stress; in vitro models; drug development; biological barriers; microfluidic; dual chamber biochip

\section{Introduction}

While neurological disorders continue to be the world's leading cause of disability and death, their associated costs are expected to exponentially increase in the coming years [1,2]. Neurology has always been one of the therapeutic areas with the highest attrition rates [3-5]. Effective brain targeting is a prerequisite for the treatment of neurological disorders [6]. One of the main difficulties is the presence of the blood-brain barrier (BBB), which restricts access to the brain for more than $98 \%$ of drugs [2]. This structural and functional barrier separates the vasculature from the central nervous system (CNS). The BBB is primarily composed of brain microvascular endothelial cells (BMEC), forming the wall of cerebral capillaries. Their particularities are the high polarization and expression of a panel of specialized interendothelial junctions, which contribute to their sealing feature.

The drug transport restrictions imposed by the BBB must be reliably predicted as early as possible in the drug development process by testing the ability of new therapeutic entities to enter the brain on relevant models. In vitro BBB models offer faster and more simplified approaches for targeted drug screening as well as for fundamental research. They 
could be humanized to overcome translatability issues. Both primary cultured BMEC and cell line models are classically used for studying the mechanisms for specific transport and kinetics of drug exchanges across the BBB. Some brain properties are maintained in freshly isolated brain capillaries but decline in culture after a few passages. Dedifferentiating processes were observed with the loss of BBB characteristics. Moreover, many BMEC lines exhibit a reduced expression of specific transporters and tight junctions, and these models are not as tight as it was observed in vivo [7].

These difficulties led to a considerable challenge for improving in vitro models with new developing technologies. The aim is to create an ideal in vitro tool that combines the benefits of both in vivo animal and in vitro human models, by mimicking the original microenvironment on a culture of human BMEC. Today, the addition of hemodynamic forces seems to be a promising way to achieve cell differentiation. Hemodynamic forces appear to be particularly important in the cell differentiation processes, as in vivo BMEC are directly and permanently exposed to the intraluminal blood flow. Blood pressure creates a tangential force across the luminal vascular endothelium called shear stress. This phenomenon underlies the activation of mechano-sensitive proteins able to convert the mechanical force into biochemical responses [8]. The endothelial response greatly varies depending on the nature and magnitude of fluid shear stress, thus generating diverse structural and functional phenotypes [9-11]. Usually, shear stress levels ranging from 5 to $23 \mathrm{dyn} \cdot \mathrm{cm}^{-2}$ are considered comparable to those reported in vivo in the brain capillaries [11-14]. It was shown that a steady unidirectional laminar flow is responsible for a quiescent endothelial response, and a subsequent better BMEC differentiation. This improves the BMEC polarization through the expression of specific BBB transporters and junctions at the luminal and/or abluminal faces of BMEC membrane. Shear stress thus contributes to the induction and maintenance of a BBB phenotype, resulting in a more physiologically relevant model [11].

Dynamic devices were created to perfuse cells with medium culture in order to provide shear stress. Although great progress has been made to develop a variety of microfluidic BBB models, nobody has recapitulated all the requirements:

- A robust, low-cost, disposable (to limit potential contaminations or substance releases), and non-removable (to ensure sealing) barrier device,

- Cultivation of a monolayer of human BMEC on a porous membrane at the interface between two compartments,

- Simple cell culture in both static and dynamic conditions with uniform shear stress to achieve BMEC differentiation,

- Compatibility with phase contrast microscopy to visualize the entire cell monolayer for monitoring cell growth and confluence, as well as confocal microscopy for characterization,

- The possibility to combine several conditions in parallel, and to sample both compartments by recovering sufficient volumes for permeability or transporter studies.

We designed, produced, and characterized a specific device that meets all the requirements mentioned above. The present study reports the development of this innovative dynamic barrier device, highlighting the significance of its design and composition in maintaining functional monolayers. This tool is intended to improve BMEC differentiation, to validate the expression and localization of some key BBB junctional proteins, and to perform permeability measurements or transport studies across this human in vitro BBB model.

\section{Materials and Methods}

\subsection{Materials}

Invitrogen, Corning, and Gibco products were purchased from ThermoFisher Scientific (Rockford, IL, USA). hCMEC/D3 cells were kindly provided by Dr. Pierre-Olivier Couraud (Inserm U1016, Cochin Institute, Paris, France). 


\subsection{Barrier Device Fabrication}

The barrier device consisted of five assembled layers, including four PMMA sheets (VOS Cell Cast Acrylic Glass, Topacryl, Schönenwerd, Switzerland) to create the upper and lower channels sandwiched between two plates and separated by a polyethylene terephthalate semi-permeable membrane with $0.4 \mu \mathrm{m}$ pores (Unique-Mem Track-Etched Membrane, Oxyphen, Chicago, IL, USA). Briefly, sheets were cut with a $\mathrm{CO}_{2}$ laser cutter (Speedy 100R, Trotec, Wels, Austria), degassed for optimal biocompatibility, and assembled using double-sided tape (3M). Each channel possessed independent in and out accesses through polycarbonate female luers (Ark-Plas, Flippin, AR, USA) embedded in the top slide with biocompatible glue (Epoxy Technology, Billerica, MA, USA). Each step of the device fabrication procedure is detailed in Supplementary Data S1. Two plate formats were created: a microscope slide format with a single condition, and a well plate format including six conditions in parallel.

3D representations of the device were performed with PTC Creo software. Matlab software (version R2020b, Portola Valley, CA, USA) was used for shear stress simulations and graphical representations.

\subsection{Endothelial Cell Culture}

Immortalized human cerebral microvessel endothelial hCMEC/D3 cell line was used as a model of the human BBB, as previously described [15,16]. hCMEC/D3 cell expansion was made until passage number 34 in Corning flasks coated with $150 \mu \mathrm{g} \cdot \mathrm{mL}^{-1}$ rat tail collagen type I (R\&D Systems, Bio-techne, Lille, France) in cold sterile water. The culture medium consisted of EBM-2 (Lonza, Basel, Switzerland) supplemented with 5\% fetal bovine serum (Eurobio-Ingen, Les Ulis, France), 1\% penicillin-streptomycin (Gibco), $1 \%$ chemically defined lipid concentrate (Gibco), $10 \mathrm{mM}$ HEPES buffer (ThermoFisher Scientific), $5 \mu \mathrm{g} \cdot \mathrm{mL}^{-1}$ ascorbic acid (Sigma-Aldrich, Saint Quentin Fallavier, France), and $1.4 \mu \mathrm{M}$ hydrocortisone (Sigma-Aldrich). A total of $1 \mathrm{ng} \cdot \mathrm{mL}^{-1}$ basic fibroblast growth factor (Sigma-Aldrich) was added extemporaneously.

The upper channel of the device was coated for one hour at $37^{\circ} \mathrm{C}$ with rat collagen type I (R\&D Systems, Bio-techne, Lille, France) diluted at $5 \mu \mathrm{g} / \mathrm{cm}^{2}$ in cold water. Both upper and lower channels were washed with DPBS (Gibco) and filled with culture medium. A total of 50,000 cells $/ \mathrm{cm}^{2}$ (165,000 cells per condition) were seeded on the membrane through the upper channel. Culture medium was renewed in all channels every $24 \mathrm{~h}$ to avoid nutrient depletion and waste accumulation. Phase contrast microscope examination was used to monitor cell confluence. After three days in a static condition, the cell monolayer reached about $80 \%$ confluence. To establish the dynamic condition, the upper channel was connected to the Ibidi pump system (Ibidi, Munchen, Germany) to unidirectionally recirculate culture medium for four days. A flow rate of $16.3 \mathrm{~mL} \cdot \mathrm{min}^{-1}$ was applied, corresponding to a shear stress of $10 \mathrm{dyn} \cdot \mathrm{cm}^{-2}$. The lower channel was filled with culture medium (no medium change was operated because the channel did not contain co-cultured cells). A static culture represents the control condition, with cells grown in coated devices for a total of seven days without connection to the pump system. Culture medium was renewed every $24 \mathrm{~h}$ in both upper and lower compartments. To resume, dynamic culture consists of three days in static to reach cell confluence, plus four days under shear stress, whereas static control involves seven days of culture in static.

\subsection{Cell Culture Characterization}

Viability test:

After washing the channels with PBS, a mix containing 1:200 propidium iodide (PI, Sigma-Aldrich), 1:200 calcein-AM (ThermoFisher Scientific) and 1:2500 hoechst 33342 (Invitrogen) in PBS was incubated for $20 \mathrm{~min}$ at $37^{\circ} \mathrm{C}$ on the upper channels containing cells. Staining was observed with a fluorescence microscope (Leica microsystems SAS, Nanterre, France). The number of cells stained for PI (dead cells, $\mathrm{PI}^{+}$) or calcein-AM (live cells, $\mathrm{C}-\mathrm{AM}^{+}$) was quantified using the "Count Particles" function in FIJI software 
(National Institute of Health). Viability was expressed in percentage as the number of viable cells $\left(\mathrm{C}-\mathrm{AM}^{+}\right)$divided by the total number of cells $\left(\mathrm{C}-\mathrm{AM}^{+}+\mathrm{PI}^{+}\right)$for each condition. Immunostaining:

To characterize the cells, immunofluorescence staining of zonula occludens (ZO-1) and $\beta$-catenin junctions was performed directly in the device. Both upper and lower compartments were washed three times with DPBS. Cells were fixed by adding 3.2\% paraformaldehyde (Electron Microscopy Sciences, Hatfield, PA, USA) in DPBS on upper channels for $10 \mathrm{~min}$, and then permeabilized with $0.1 \%$ Triton X-100 (ThermoFisher Scientific) for $10 \mathrm{~min}$. Rabbit-anti-ZO-1 (ref. 617300, Invitrogen) or rabbit anti- $\beta$-catenin (ref. ab32572, Abcam, Cambridge, UK) primary antibodies were incubated at 1:200 with $2 \%$ Bovine Serum Albumin (BSA) in DPBS for $1 \mathrm{~h}$. A mix of 555 anti-rabbit IgG Alexa Fluor 555 secondary antibody (Invitrogen) at 1:500, Alexa Fluor 488 Phalloidin (Invitrogen) (labelling F-actin) at 1:500, and $1 \mu \mathrm{g} \cdot \mathrm{mL}^{-1}$ hoechst 33342 (Invitrogen) (labelling nuclei) with 2\% BSA in DPBS was incubated in the same channel for $1 \mathrm{~h}$. Between each incubation, channels were washed three times with DPBS. The upper channel was filled with $95 \%$ glycerol (Invitrogen) in DPBS and kept at $4{ }^{\circ} \mathrm{C}$ until acquisition.

For immunodetection, the spinning disk system Yokogawa CSU-W1 integrated in Metamorph software (Molecular Devices) was mounted to the camera port Nikon Ti-E inverted microscope. Objectives with working distance $\geq 0.61 \mathrm{~mm}$ can be used to see the cells on this device, which were directly placed above the objective for detection through the baseplates of the device. A Z-dimension series of images were taken and processed using FIJI software. Images were taken with the same acquisition parameters for all conditions and no detectable signal was observed in the absence of primary antibodies.

\subsection{Permeability Measurement}

Lucifer yellow (LY, Sigma-Aldrich) was used as a marker of paracellular transport. Experiment was performed in duplicate according to the method previously described [17], after seven days of cell culture in static and dynamic conditions in parallel.

Briefly, both compartments were washed and filled with Ringer-HEPES buffer $(150 \mathrm{mM}$ $\mathrm{NaCl}, 5.2 \mathrm{mM} \mathrm{KCl}, 2.2 \mathrm{mM} \mathrm{CaCl} 2,0.2 \mathrm{mM} \mathrm{MgCl}_{2}-6 \mathrm{H}_{2} \mathrm{O}, 6 \mathrm{mM} \mathrm{NaHCO} 3,5 \mathrm{mM} \mathrm{HEPES}$, $2.8 \mathrm{mM}$ glucose, $\mathrm{pH}$ 7.4). At $\mathrm{t}=0$, the upper compartment was filled with $\mathrm{LY}$ at $100 \mu \mathrm{M}$. The devices were incubated at $37^{\circ} \mathrm{C}$ for $30 \mathrm{~min}$. At each time point (10, 20, and $\left.30 \mathrm{~min}\right)$, the buffer contained in the lower compartment was collected with a syringe and immediately replaced by fresh buffer. At the end of the incubation, both compartments were sampled.

Fluorescence intensities were analyzed by spectrofluorimetry $(444 \mathrm{~nm}$ excitation and $538 \mathrm{~nm}$ emission wavelengths), and LY concentrations for each time point were extrapolated from a calibration curve. The endothelial apparent permeability (Papp) was calculated using the following equation [18]:

$$
\operatorname{Papp}\left(\mathrm{cm} \cdot \mathrm{s}^{-1}\right)=\frac{\triangle C V}{\triangle t} \times \frac{1}{A C_{0}}
$$

where

C: cumulative LY concentrations $\quad A$ : membrane surface area

$V$ : lower compartment volume $\quad C_{0}$ : Initial LY concentration

$t$ : incubation time

Results are presented as mean \pm standard deviation. The percentages of recovery provide an indication about the nonspecific binding of the LY to cells and material. Recovery was obtained by dividing the sum of the LY concentrations at each time point by the initial LY concentration, and expressed as a percentage. Statistical significance was attested by Student T-test when $p<0.05$. 


\section{Results}

\subsection{Barrier Device Design}

Two channels were reproduced with a semi-permeable membrane interface. To enable a permanent visual control of the whole membrane surface, rectangular and superimposed channels were designed. The upper channel is straight to avoid any flow turbulence, while the lower channel is S-shaped (as presented in Figure 1a). BMEC are seeded in the upper channel to recover the semi-permeable membrane, allowing the exchanges with the lower channel.
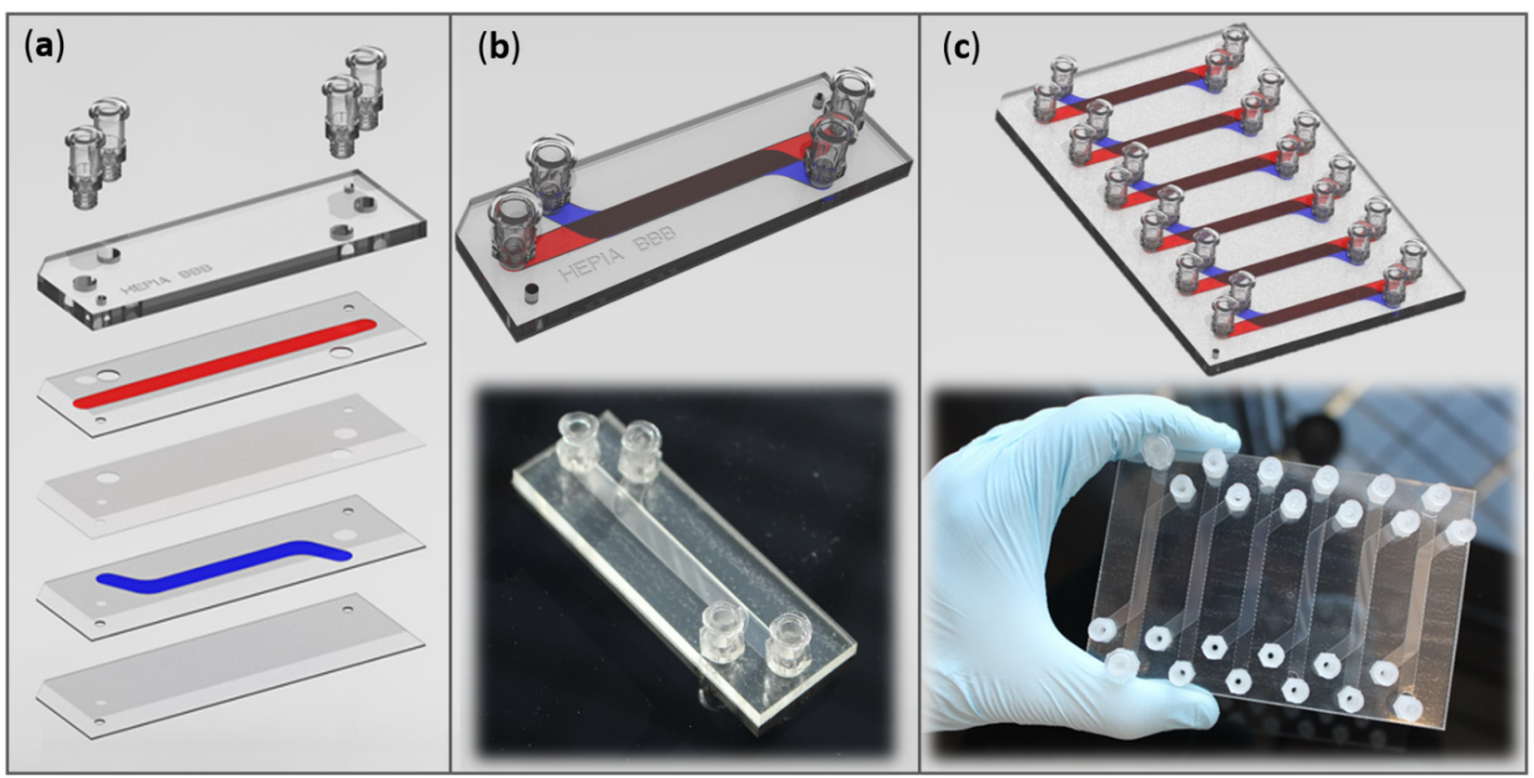

Figure 1. Fluidic barrier device representations. (a) Exploded view of the different parts of the barrier device before assembling. (b) Pictures and 3D representations of our home-made barrier device in microscope slide format and (c) in plate format (encompassing six conditions in parallel). The upper channel is represented in red, and the lower one in blue. Device modelling was carried out with PTC Creo software.

Two formats were imagined: a microscope slide-format containing one condition (Figure 1b), and a classic plate-format combining six conditions in parallel (Figure 1c).

For the BMEC culture, several important parameters were considered, including the materials used, the geometry and dimensions of the cellular compartment, and the fluidic parameters.

\subsubsection{Materials for Device Fabrication}

All materials were chosen to ensure biocompatibility and optical transparency throughout the device.

The device is made of superimposed polymethyl methacrylate (PMMA) sheets. This rigid thermoplastic is biocompatible, cost-effective, suitable for mass fabrication, and has excellent optical performance of light transmission [19,20]. A panel of different thicknesses of PMMA sheets is available. Sheets were cut by a laser process to be adapted according to our design.

The optically transparent polyester membrane with a $0.4 \mu \mathrm{m}$ pore size was chosen as the interface to allow the exchanges between both compartments. Firstly, its transparency ensures the visualization of the cell monolayer throughout the device by phase contrast microscopy. This point is important to conveniently monitor viability, growth, and confluence over the culture time. Secondly, this material is classically used in Transwell ${ }^{\circledR}$ inserts. Cell culture conditions were optimized for hCMEC/D3 cell culture (including pore density and size, collagen coating, cellular adhesion, and cell growth) [18,21]. 


\subsubsection{Channel Dimensions}

\section{Channel lengths:}

For biological experiments, enough cells are needed to allow representative populationbased analyses, and this implies a larger channel culture region. The channel lengths were adapted to take advantage of the entire length of a classic microscope slide (corresponding to the width of a classic plate). Therefore, the length of the upper channel was defined at $63 \mathrm{~mm}$ for a sufficient cell population. The contact surface between the two channels was made as large as possible so that most of the seeded cells should be in contact with the lower compartment. The two compartments can exchange along $39.4 \mathrm{~mm}$, representing more than $62 \%$ of the cell monolayer.

Channel width $(w)$ :

The particularity of channel-based devices, in contrast to conventional wells and Transwell ${ }^{\circledR}$, is the higher edge area compared to low volumes. The geometry of the cell culture region highly influences the flow profile. In a non-cylindrical channel, the height-towidth $(h / w)$ ratio of the cross section is an important consideration because it impacts on the shear stress distribution on the cell monolayer. When the medium flows in a rectangular channel, the velocity tends towards zero at the walls. This phenomenon generates two main issues. First, the cells growing near the side walls undergo a lower shear stress than the cells at the middle of the channel, which could consequently induce differences in cell behavior and measured permeability. Moreover, we may fear a longer retention time of paracrine signaling agents and analytes for permeability measurements at the walls. To limit these effects, the width of the channel cross section $(w)$ must be much greater than its height $(h)$ for a minimal $h / w$ ratio [22,23]. In our configuration, the thickness of PMMA sheets determines the channel heights. Lower available thicknesses are $0.3,0.5$, and $0.6 \mathrm{~mm}$, so we defined the width $w$ at $5 \mathrm{~mm}$. Therefore, the $h / w$ ratio was included between 0.06 and 0.12 . This parameter is very important to achieve the most uniform shear stress across the entire cell surface. The uniformity of the shear stress distribution in our channel is analyzed below.

With this length and width, we obtained a seeding area of $3.26 \mathrm{~cm}^{2}$, allowing to have enough cells for permeability studies or genetic material extraction for expression analysis, for example.

Upper channel height $(h)$ :

Our workflow consisted of growing the cells in static condition for further days until confluence, before connecting the channel to a pump system for medium recirculation. In classic flasks and wells, large volumes of media limit the depletion of growth factors and nutrients contained in the medium, and dilute the waste products generated by cells. At the microscale, the channels have restricted dimensions, thus reducing the volume of medium above the cell surface. Consequently, the medium must be replenished more regularly to ensure nutrient supplying and waste elimination over the culture time in static.

To measure the necessary volume of media for our cells, we applied the concept of "effective culture volume and time" introduced by Beebe et al. [24]. During the culture of hCMEC/D3 cells in flasks, we classically use $200 \mu \mathrm{L} / \mathrm{cm}^{2}$ of medium (i.e., $5 \mathrm{~mL}$ in a T25 format or $15 \mathrm{~mL}$ in a T75 format), with a replenishment every four days. Consequently, cells use $50 \mu \mathrm{L}$ per $\mathrm{cm}^{2}$ per day. According to the previous defined length and width, the area of cell seeding represents $3.26 \mathrm{~cm}^{2}$ in our device. In order to have $50 \mu \mathrm{L}$ of medium per $\mathrm{cm}^{2}$ and per day, the channel must contain $163 \mu \mathrm{L}$ of medium changed every day. This results in a volume of $163 \mathrm{~cm}^{3}$ on $3.26 \mathrm{~cm}^{2}$ of the cell surface, so the channel height $(h)$ must be $0.5 \mathrm{~mm}$. If we chose a smaller $h$, the volume medium would be insufficient for one day of supply, so we would have to change the medium more frequently than once a day. To illustrate this point, a spreadsheet with the different heights is presented in Table 1. 
Table 1. Comparison of effective culture volumes and times between flasks and our home-made device (including further proposed heights of the upper channel $(h)$ ). Medium heights in flasks were calculated by dividing the volume by the cell surface, while medium heights in devices corresponded to the height of the upper channel as it was filled with medium. Interval between medium change in flask corresponds to $50 \mu \mathrm{L} / \mathrm{cm}^{2} /$ day. ${ }^{*}$ Usual volumes recommended by the supplier. (Wells and Transwell ${ }^{\circledR}$ cannot be taken into consideration because of the bias of the meniscus effect).

\begin{tabular}{|c|c|c|c|c|}
\hline \multicolumn{5}{|c|}{ Effective Culture Volumes and Times: } \\
\hline Material for Culture & $\begin{array}{l}\text { Cell Seeding Surface } \\
\qquad \mathrm{cm}^{2}\end{array}$ & $\begin{array}{c}\text { Volume } \\
\text { mL }\end{array}$ & $\begin{array}{l}\text { Medium Height } \\
\qquad \mathrm{cm}\end{array}$ & $\begin{array}{c}\text { Interval between Two } \\
\text { Medium Changes } \\
\text { Hours }\end{array}$ \\
\hline T75 Flask & 75 & $15^{*}$ & 0.2 & 96 \\
\hline T25 Flask & 25 & $5 *$ & 0.2 & 96 \\
\hline Barrier device with $h=0.6 \mathrm{~mm}$ & 3.26 & 0.196 & 0.06 & 29 \\
\hline Barrier device with $h=0.5 \mathrm{~mm}$ & 3.26 & 0.163 & 0.05 & 24 \\
\hline Barrier device with $h=0.3 \mathrm{~mm}$ & 3.26 & 0.098 & 0.03 & 14 \\
\hline
\end{tabular}

Lower channel height:

In order to characterize the BBB properties of the cells, it is very important to observe the formation of the tight junctions, which is a witness of cell differentiation. Such an observation has to be made directly through the underside of the device. Objectives to visualize with confocal microscopes generally accept focal distances up to $0.7 \mathrm{or} 1 \mathrm{~mm}$. The shorter the focal distance is, the better the quality of imaging will be. Thus, for a good confocal observation of tight junction immunostainings, the distance between the cell monolayer and the objective (corresponding to the height of the lower channel and the baseplate) must be as small as possible. We consequently adopted PMMA sheets with the lowest possible height of $0.3 \mathrm{~mm}$ to form the lower channel and the baseplate. Thus, taking into account the adhesive thickness of $0.05 \mathrm{~mm}$, the focal distance between the cell surface and the objective is $0.7 \mathrm{~mm}$. This important parameter allows to use confocal imaging to characterize some BBB marker proteins.

To conclude, the final dimensions result in a compromise between all these considerations to meet the entire list of requirements.

\subsection{Flow Profile}

Pump system:

The accesses of the upper and lower channels were standardized with luers for easy pipetting and possible adaptation to most of the pump systems. Luers were integrated on each side of the channels, resulting in the possibility to perfuse both channels independently (in this study, only the channel receiving cells was perfused). Inlets and outlets were placed in line with the perfused channel to avoid any flow disturbance [25].

The Ibidi pump system was chosen to drive a constant flow unidirectionally (oscillating flow is considered more suitable for vessel defects, and pulsatile flow was shown to be responsible for alterations in the BMEC phenotype [10]). This system combines the advantages of a syringe pump (bubble trap, visual rapid control of the flow rate due to the graduated syringes), with the possibility to recirculate the flow with reduced dead volumes. We can note that a brief interruption in flow occurs when the syringes switch due to the pinch valve activation. This unavoidable phenomenon creates a very slight pulse that can be neglected in comparison with the long phases of constant flow.

The software precisely controls the pressure and records it per minute in a file. The Ibidi pump system provides a wide range of flow rates from 0.09 to $52.5 \mathrm{~mL} \cdot \mathrm{min}^{-1}$, thanks to the different tubing thicknesses available.

One pump can drive simultaneously until four fluidic units with independent flow parameters, and one fluidic unit can connect up to three channels in series. Consequently, we can use up to 12 channels under flow simultaneously. Fluidic setups for devices in well plate format and microscope slide format are shown in Figure 2a,b. For visual monitoring 
of cells, a tubing of $50 \mathrm{~cm}$ length allows to put the device on the microscope stage without interrupting the shear stress (the fluidic unit stay in the incubator). In addition, it is possible to integrate this system into a live cell culture microscopy platform for real-time imaging.

Flow rate:

In our device, the flow can be applied to both channels. Here, we present our calculations to set up the upper channel, as it receives the cells (that recover the porous membrane at the bottom of the channel).

Depending on the flow rate $(Q)$ configured on the pump system, cells are submitted to a proportional shear stress $(\tau)$. Shear stress is defined by the product of the medium viscosity $\left(\mu=0.72 \times 10^{-3} \mathrm{~N} \cdot \mathrm{s} \cdot \mathrm{m}^{-2}\right.$ for culture medium at $37{ }^{\circ} \mathrm{C}$ with $10 \%$ of serum) and the shear rate $(\partial v / \partial y$, which corresponds to the change in flow velocity through the channel) $[23,26]$.

$$
\tau_{(x, y)}=\mu \frac{\partial v(x, y)}{\partial y}
$$

While in circular channels, the shear stress is easy to calculate, the formula is more complex for rectangular channels due to the lateral walls that reduce the flow velocity. Based on the precise formula to calculate the flow rate in a rectangular channel [27], we express the shear stress according to the geometric properties of the channel ( $h$ and $w$, as previously defined). The following equation determines the shear stress at any point of a rectangular channel:

$$
\tau_{(x, y)}=\mu \frac{Q}{S} \sum_{n=0}^{\infty} \frac{(-1)^{n} b \pi}{(2 n+1)^{2}}\left(\frac{2}{\pi}\right)^{3} \frac{\sin a\left[(2 n+1) \frac{\pi y}{2 b}\right]}{\cos a\left[(2 n+1) \frac{\pi h}{2 b}\right]} \cos \left[(2 n+1) \frac{\pi x}{2 b}\right]
$$

with:

$$
S=a b^{3} \frac{4}{3}\left(1-\frac{192}{\pi^{5}} \frac{b}{a} \sum_{n=0}^{\infty}\left\{\frac{1}{(2 n+1)^{5}} \tan a\left[\frac{(2 n+1) \pi a}{2 b}\right]\right\}\right)
$$

A coordinate cross is imagined at the center of the channel, as illustrated in Figure 2c. We defined $2 a$ as the height of the channel in the direction of the $y$-axis, $2 b$ as the width of the channel in the direction of the $x$-axis, and the $z$-axis represents the direction of the flow. Cells seeded on the channel are located on the membrane surface: the bottom of the channel $(y=-a)$. Microvascular endothelial cells have a very small thickness (from 0.3 to $0.5 \mu \mathrm{m}$ [28]), which can be neglected for these measurements. Likewise, the height at the center of the BMEC is greater than at the cell walls due to the presence of the nucleus, but this variability stays inferior to $0.5 \mu \mathrm{m}$. Indeed, it is not considered as roughness and does not affect the laminarity.

Firstly, we estimated the range of possible shear stresses according to the flow rates proposed by the Ibidi pump system. We used the above equations for the minimum and maximum possible flow rates $\left(0.09\right.$ and $\left.52.2 \mathrm{~mL} \cdot \mathrm{min}^{-1}\right)$ for the cells located at the center of the membrane (i.e., $x=0, y=-a$ ) in our device. The results were 0.055 and $32.3 \mathrm{dyn} \cdot \mathrm{cm}^{-2}$. This confirms that our setup can deliver a large panel of shear stresses and covers the physiological range. The calibration curve in Figure $2 \mathrm{~d}$ shows the flow rate to set depending on the desired shear stress. For the experiments presented here, the flow rate was configured at $16.3 \mathrm{~mL} \cdot \mathrm{min}^{-1}$ to acquire a physiological pressure of $10 \mathrm{dyn} \cdot \mathrm{cm}^{-2}$ on the cell surface seeded in our barrier device. 
(a)

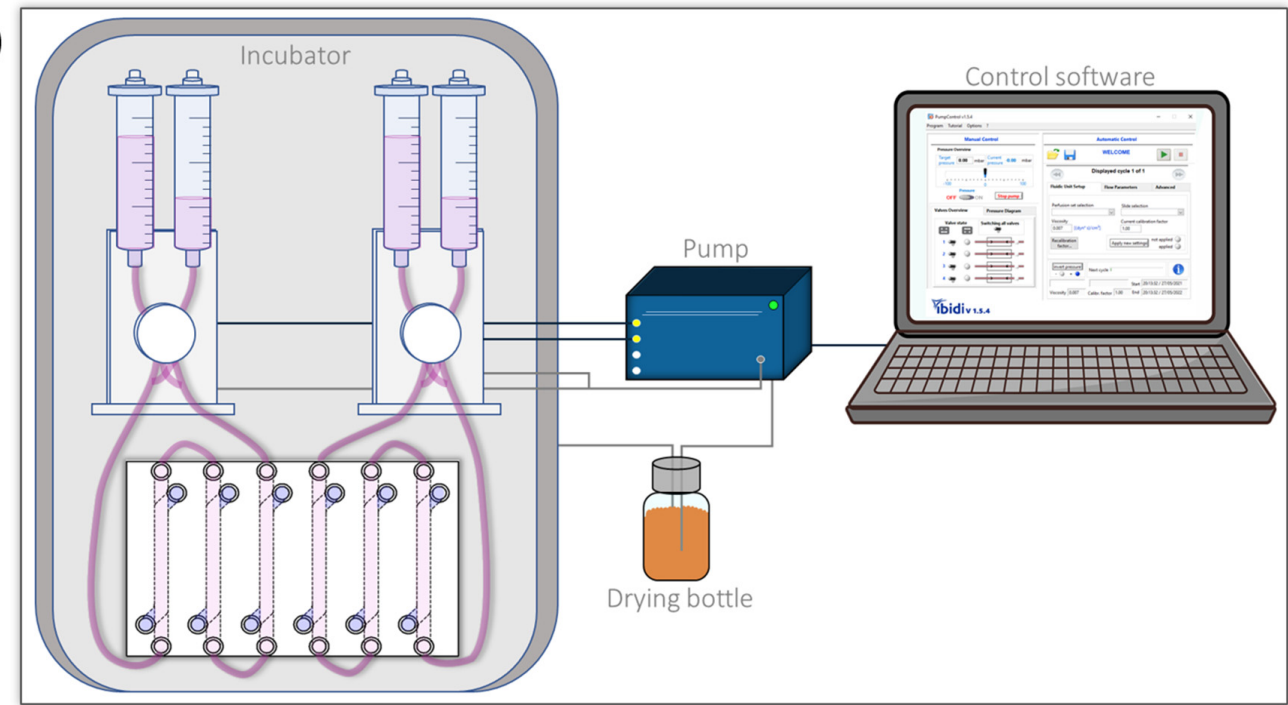

(b)

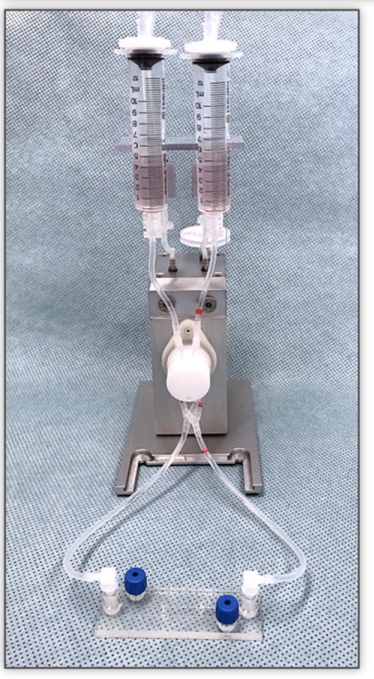

(d)

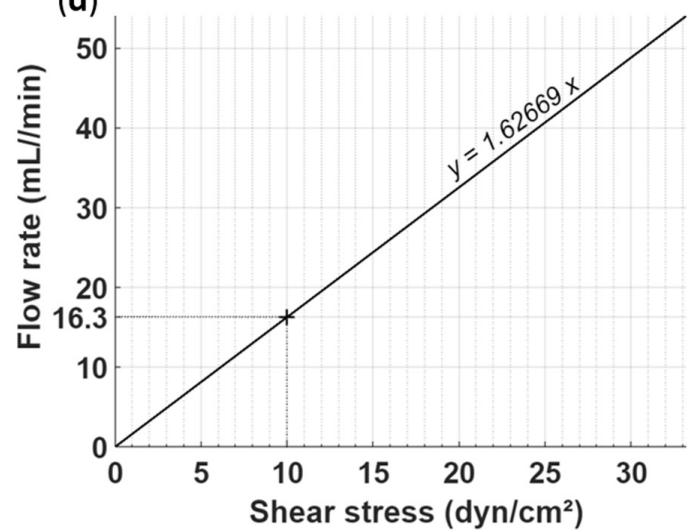

(c)

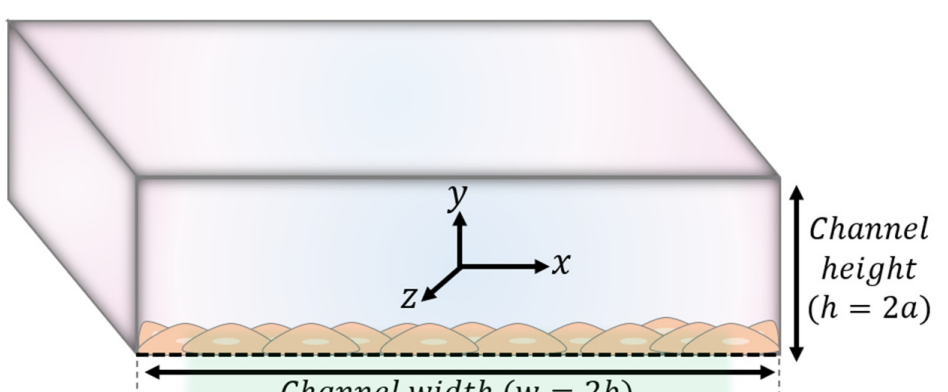

Channel width $(w=2 b)$

(e)

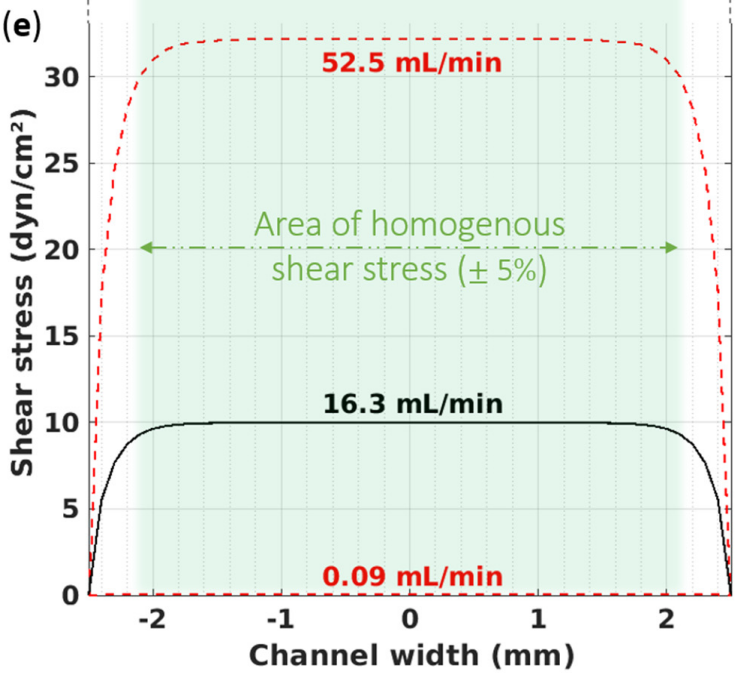

Figure 2. Fluidic setup. (a) Representation of the fluidic equipment for our barrier device in well plate format. The Ibidi pump is controlled by the specific software and simultaneously drives two fluidic units with independent flow parameters. Two fluidic units connect six channels. (b) Picture of our barrier device in microscope slide format connected to a fluidic unit. (c) Illustration of the orthonormal coordinate system necessary for the flow calculations in the channel cross section. (d) Calibration curve of the flow rate to implement according to the intended shear stress on the cell monolayer. For 10 dyn $\cdot \mathrm{cm}^{-2}$ in our barrier device, we must configure a flow rate of $16.3 \mathrm{~mL} \cdot \mathrm{min}^{-1}$. This calculation depends on the geometry of the seeding channel and parameters of the culture medium perfused. (e) Prediction of area of uniform shear stress along the channel width on the cell monolayer. Ibidi pump system can provide flow rates from 0.09 to $52.5 \mathrm{~mL} \cdot \mathrm{min}^{-1}$ (corresponding to a range of 0.055 to $32.3 \mathrm{dyn} \cdot \mathrm{cm}^{-2}$ ). Shear stress is distributed homogenously on $82 \%$ of the channel width. 
As discussed above, in a rectangular channel, the shear stress is not uniform along the channel width because of the presence of side walls. Precautions must be taken with the shear stress distribution to avoid exposing cells to an inhomogeneous shear stress field $[22,29]$. The characterization of the flow profile in our device guarantees a convenient and accurate control of the flow. We therefore modeled the shear stress values to which the cells are exposed, according to their position on the membrane. The graph in Figure 2e depicts the distribution of the shear stress above the cells (i.e., for all $x, y=-a$ ) for the minimum and maximum flow rates and for our experiment at $10 \mathrm{dyn} \cdot \mathrm{cm}^{-2}$. We observed flat flow profiles due to the low $h / w$ channel ratio, showing that most of the cells are exposed to the predicted shear stress. By granting a variability of $5 \%$, only the cells located at $\leq 450 \mu \mathrm{m}$ of the side walls will experience a lower shear stress than the other cells. In our device, the correct shear stress covers $82 \%$ of the entire cell monolayer, independently of the flow rate configured. We studied the shear stress distribution for other BBB devices to compare our data. We revealed large differences in percentages of shear stress homogeneity due to the high variety of channel dimensions. A very good shear stress homogeneity of $90 \%$ was predicted for one device [30], while other devices present identical [31] or lower [32-40] homogeneity percentages compared to ours. This comparison allows us to support the fact that our device presents one of the larger areas of homogenous shear stress. (Supplementary Data S2 provides more detailed information about these calculations).

Laminarity:

In physiological condition, the blood flow circulates laminarly throughout most of the circulatory system [29]. The Reynold's (Re) number determines whether the fluid flow is laminar or turbulent in our device. The dimensionless $R e$ is expressed as:

$$
R e=\frac{\rho V h}{\mu}
$$

with

$$
V=\frac{Q}{h w}
$$

where

$$
\begin{array}{ll}
\rho: \text { culture medium density }\left(993 \mathrm{~kg} \cdot \mathrm{m}^{-3}\right) & \mu \text { : dynamic viscosity }\left(0.72 \times 10^{-3} \mathrm{~kg} \cdot \mathrm{m}^{-1} \cdot \mathrm{s}^{-1}\right) \\
\left.V: \text { flow velocity (in } \mathrm{m} \cdot \mathrm{s}^{-1}\right) & Q: \text { flow rate }\left(\text { in } \mathrm{m}^{3} \cdot \mathrm{s}^{-1}\right) \\
h \text { : channel height }\left(0.5 \times 10^{-3} \mathrm{~m}\right) & w \text { : channel width }\left(5 \times 10^{-3} \mathrm{~m}\right)
\end{array}
$$

The result gives Re numbers from 0.30 to 174 for the flow rate panel ranging from 0.055 to $32.3 \mathrm{dyn} \cdot \mathrm{cm}^{-2}$. For an experiment at $10 \mathrm{dyn} \cdot \mathrm{cm}^{-2}$, the Re number is 54.2 . The transition to the turbulence typically appears when the Re number exceeds 1400 [41]. Here, the values stay sufficiently below this threshold, proving that the flow is laminar over the entire cell monolayer, whatever the configured flow rates.

\subsection{Cell Culture}

The thorough design of our new fluidic device provides uniform shear stress to help the BMEC differentiation for a better human BBB model. hCMEC/D3 cells were seeded through the upper channel coated with type IV collagen. Cells adhered on the porous membrane and grew for three days until they formed a fully confluent cell monolayer. Then, cells were exposed to the flow for four additional days for an optimal differentiation. In parallel, control conditions were maintained in static culture with medium change. Physiological $\mathrm{CO}_{2}$ levels and temperature were provided and monitored directly from the incubator controls. The $\mathrm{pH}$ of the media was measured with standard laboratory equipment after seven days of culture in static or dynamic conditions. It indicated a relatively constant physiological value around 7.2 and 7.4, showing no medium deterioration. Viability was assessed with a live/dead assay and depicted a satisfactory average rate of $90.3 \pm 6.6 \%$ in static and $94.5 \pm 3.7 \%$ in dynamic condition after seven days of culture. These results show that the device is suitable for cell culture. 
Phase contrast microscopy was used daily to monitor morphology, viability, and growth. An example of our field of vision is presented in Figure 3, after seven days of dynamic culture at $10 \mathrm{dyn} \cdot \mathrm{cm}^{-2}$. Cells are clearly visible above the membrane pores.

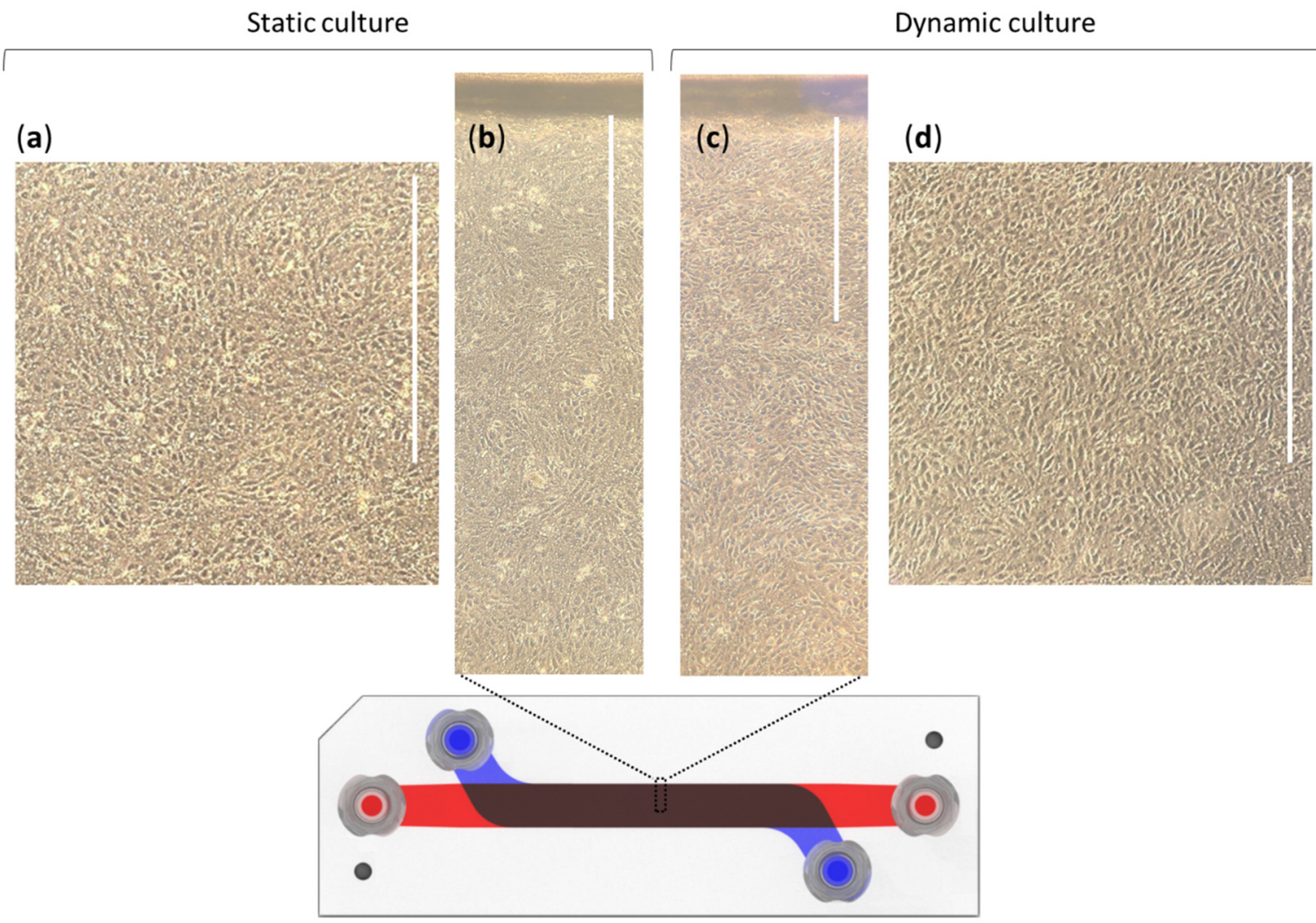

Figure 3. Phase contrast microscopic views of the static and dynamic $\left(10 \mathrm{dyn} \cdot \mathrm{cm}^{-2}\right)$ cultures of hCMEC/D3 cells after seven days in the barrier device; $(\mathbf{a}, \mathbf{d})$ images were taken from the center of the channels, while $(\mathbf{b}, \mathbf{c})$ were viewed at the edges. These images are representative of four independent experiments. Scale bars represents $1 \mathrm{~mm}$.

Both in static and dynamic conditions, images exhibited confluent cell monolayers. hCMEC/D3 cells exposed to shear stress appear more elongated from the first hours of flow. The regions in the same image show various cellular alignments. We investigated this point by a cell orientation analysis detailed in Supplementary Data S3. It reveals that cells in static condition do not have any preferential alignment, whereas those in dynamic condition orientate particularly in the channel axis (around $0^{\circ}$, corresponding to the direction of flow). This significant change in orientation is an indicator of an effective exposure to the flow, as previously observed with hCMEC/D3 cells [42]. It confirms that cells are able to sense and respond to flow in our device.

This environment is relevant for the culture of BMEC until at least eight days, by retaining viability and typical morphology.

\subsection{Validation of Specific Junctional Markers}

After culture time, we observed the expression and localization of important junctional proteins to validate the cell differentiation. The particularity of BMEC is their high localized expression of tight and adherent junctions at intercellular spaces. Claudins, occludin, and its associated protein zonula occludens- 1 (ZO-1) constitute the major tight junctions at the $\mathrm{BBB}$, sealing the paracellular space. As claudins and occludin are expressed to a less extent in hCMEC/D3 cells [43,44], we first focused on ZO-1 immunodetection. Concerning adherent junctions, the b-catenin was preferred to VE-cadherin as its expression is highly dependent upon the culture conditions [45,46]. Together, ZO- 1 and $\beta$-catenin are mainly used as specific markers to validate BBB differentiation as there are key structural compo- 
nents $[34,38,42,47]$. Immunostaining procedures were performed at the end of the culture by incubating several antibodies after fixation of the cell monolayer. Precise visualization operated directly through the device (by crossing the underside of the membrane) with a spinning-disk confocal microscope. Results are shown in Figure 4.

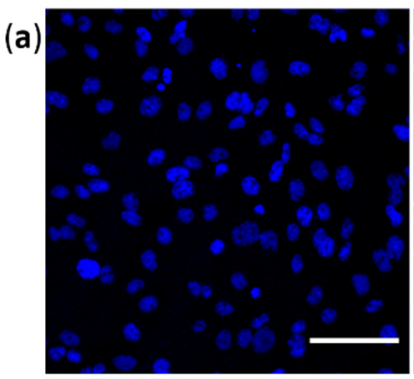

(b)

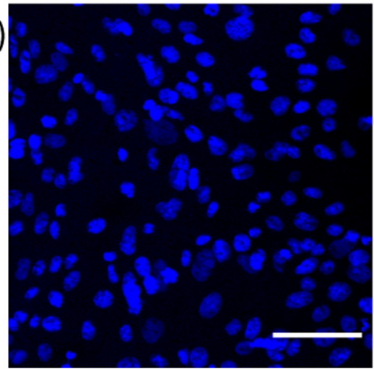

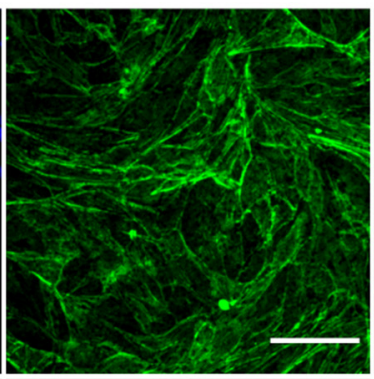

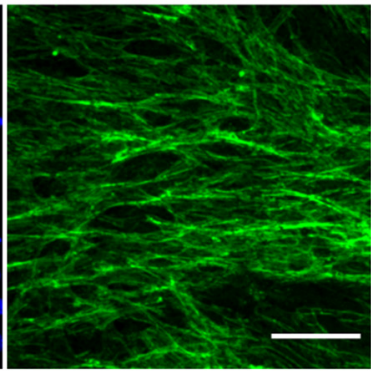

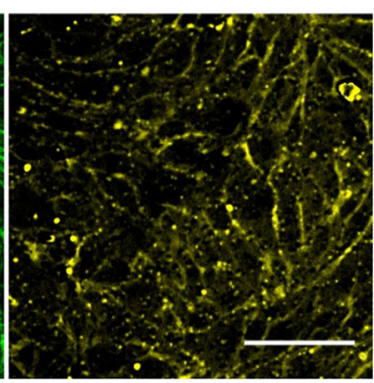
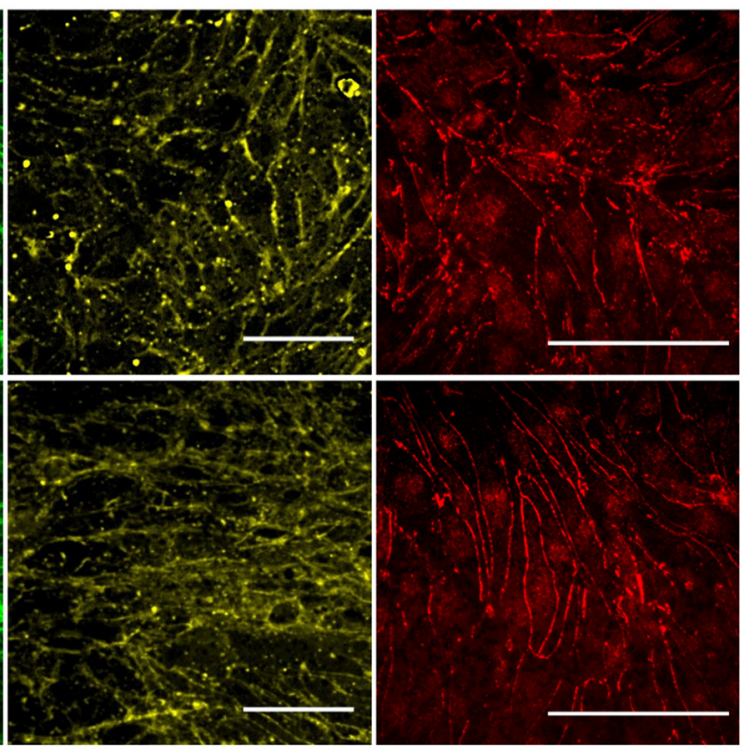

Figure 4. hCMEC/D3 cells cultured for seven days (a) in static condition or (b) including four days of shear stress exposure at $10 \mathrm{dyn} \cdot \mathrm{cm}^{-2}$ (flow direction is horizontal). Immunostaining was performed and observed directly in our home-made barrier device with a spinning disk confocal microscope. From the left to the right: nuclei in blue, F-actin in green, $\beta$ catenin adherent junction in yellow, and ZO-1 tight junction in red (providing from distinct experiment). Each image is representative of at least two independent experiments. Scale bars represent $50 \mu \mathrm{m}$.

Nuclei staining are uniformly distributed in both conditions, demonstrating intact cell monolayers after seven days of culture. Phalloidin staining reveals elongation of the actin strains only in the dynamic condition. Both tight and adherent junctions are localized at the cell-to-cell boundaries, but also in the nucleus for ZO-1 (in accordance with previous staining [43]). The ZO-1 tight junction appears more continuous along the inter-endothelial contacts, while $\beta$-catenin adherent junction seems more homogenous and regular in the dynamic condition. We can note the presence of some punctuate signals in the $\beta$-catenin images which were also observed in well plate support (data not shown). In our opinion, this artefact provides from the antibody that nonspecifically aggregates due to dissolution problems.

All images in dynamic condition show a more elongated cellular morphology, whereas it is not observed in static condition, as demonstrated above. These confocal images taken with high magnification confirm that in dynamic condition, while most cells align in the flow direction (as in actin fibers and $\beta$-catenin images), some cells in a few regions exhibit another orientation, sometimes perpendicular to the flow direction, as observed in $\mathrm{ZO}-1$ staining. We confirmed the expression of these key BBB markers after seven days of culture. Our observations showed that the $\mathrm{ZO}-1$ and $\beta$-catenin scaffolding proteins are more finely expressed in dynamic culture, which correlate with a more successful BMEC differentiation.

\subsection{Permeability Study}

After validating some key BBB characteristics, permeability measurements can be performed. We used lucifer yellow (LY), a small molecule known to exhibit a restricted paracellular transport at the BBB, to demonstrate the feasibility of this type of experiment in our device. LY was incubated in the upper compartment for 30 min to estimate the endothelial paracellular permeability. Results are reported in Table 2. 
Table 2. Results from lucifer yellow (LY) permeability measurement in hCMEC/D3 cells maintained for seven days in our barrier device. Experiment was performed in duplicate on cells cultured in static or dynamic condition (under shear stress of $10 \mathrm{dyn} \cdot \mathrm{cm}^{-2}$ ). Results are given as means \pm standard deviation. Recovery percentages estimated the loss of LY during the experiment due to LY non-specific binding. Apparent endothelial permeability (Papp) was calculated as previously described [18]. *: Student $p$-value $<0.05$.

\begin{tabular}{|c|c|c|}
\hline Culture Condition & Recovery (\%) & $\operatorname{Papp}\left(10^{-6} \mathrm{~cm} \cdot \mathrm{s}^{-1}\right)$ \\
\hline Cells in static culture & $87.3 \pm 0.36$ & $14.2 \pm 0.66$ \\
\hline Cells in dynamic culture & $86.6 \pm 2.99$ & $10.2 \pm 1.11$ * \\
\hline
\end{tabular}

The recovery values up to $85 \%$ suggest that adsorption on the channel surface remains low in our barrier device. hCMEC/D3 apparent permeabilities (Papp) are consistent with data previously reported [21]. The Papp in the dynamic condition $(10.2 \pm 1.11 \times$ $\left.10^{-6} \mathrm{~cm} \cdot \mathrm{s}^{-1}\right)$ was significantly lower than the one in the static condition $(14.2 \pm 0.66 \times$ $10^{-6} \mathrm{~cm} \cdot \mathrm{s}^{-1}, p$-value $<0.05$ ), which correlates with a tighter barrier, as noticed above. This experiment attests to the ability to perform transport assays in our home-made fluidic device.

\section{Discussion}

The application of physiological laminar shear stress on cellular models has been shown to optimize the cell differentiation and ameliorate their predictive value through reproduction of the in vivo shear force. To culture the BMEC under flow, we can benefit today from a wide range of dynamic devices whose features and possible uses greatly differ [48]. Below is an overview of the major parameters of existing devices created to perform permeability studies.

A first approach was to integrate the fluidic component into the classically used inserts. A few devices were engineered by implementing fluid movement either inside or below Transwell ${ }^{\circledR}$ inserts $[49,50]$. However, these complex architectures make the shear stress impossible to calculate, and are prone to turbulences [51]. These models based on Transwell ${ }^{\circledR}$ inserts therefore do not allow to endure physiological shear stress ranges.

Then, microfluidic devices were created to reproduce the architecture of two compartments separated by BMEC for analyzing the movement of substances across the BBB. According to the disposition of the channels, these devices can be classified as: horizontally aligned channels, crossed channels, or vertically aligned channels.

In side-by-side configurations, channels are next to each other in the same horizontal plane. BMEC are seeded on the entire channel surface, but only a portion of them is in contact with the adjacent compartment. Consequently, the exchanges with the other compartment are only on one side. In addition, this configuration does not allow to visualize the cell-cell contacts at this interface along the culture time $[36,39,40,52,53]$.

Devices based on crossed channels, i.e., perpendicularly superimposed, have the benefit of allowing the visualization of the entire cellular interface between the compartments. However, the overlapping area between the two compartments is too small compared to the entire seeding surface, resulting in a minor number of cells in contact with the other compartment $[30,34,54]$.

Finally, vertically superimposed channels represent the perfect configuration combining a larger contact surface between the two compartments, with the possibility of morphological examination on the entire cell monolayer. A few published devices present this ideal configuration but show some drawbacks on the experimental setups $[32,35,37,38,55]$, discussed below.

The equation derived from the Haagen-Poiseuille formula $\left(\tau=6 \mu \theta / w h^{2}\right)$ is widely used to configure the flow rate depending on the desired shear stress in microfluidic models. It depicts an average value specifically in case of special channel dimensions, but does not consider the heterogeneity of shear stress distribution [56]. Actually, cells can be subjected to 
strong variations along the channel width. To prevent this effect, dimensions of the fluidic channel must be defined to form a rectangular cross section $(w>>h)$ [48]. Furthermore, it is important to predict the flow profile according to the channel dimensions to configure reliable flow rate values [42]. The choice of a parallel static control is important for comparison to the fluidic condition, but is often lacking due to the device characteristics $[31,32,35,39,52,53]$. In some cases, Transwell ${ }^{\circledR}$ assays are used but do not represent an accurate control because of large differences in terms of format, material, and surface area to volume ratio [34,37,54,57]. In addition, the duration of the culture and the medium exchange have to be identical for a suitable comparison.

To overcome all these points, we created a device for culturing BMEC under physiological shear stress to help their differentiation, and characterize them before performing permeability studies.

Two vertically superimposed channels were designed for direct visual observation at any time of the culture. The channel lengths were defined to implement a large exchange surface between both compartments. It provides sufficient volumes for sampling during experiments, but also to collect cells or genetic material for further analysis. The heights of the channels were adapted for easy cell maintenance, and to allow a direct characterization of BBB markers by confocal microscopy. The width of the channels ensures a physiological shear stress homogenously distributed along the channel.

Our device configuration allows an easy cell culture of any cell type, both in the upper and/or lower channels. Here, we seeded human cerebral endothelial (hCMEC/D3) cells on the porous membrane at the interface between the channels. The barrier device is compatible with any pump system and can support a wide range of shear stresses (including physiological values) while ensuring laminarity. All along the culture, optical microscopy was used to monitor cellular organization and confluence. We confirm the hCMEC/D3 cell realignment in the flow direction, and demonstrate that culture in the static condition is also suitable with a daily renewal of culture medium.

BMEC characterization was studied directly in the device by immunodetection of both tight and adherent junctions at cell-to-cell boundaries. As for quality control, cells can also be extracted to isolate nucleic acids or proteins for further exploration of specific BBB markers in both conditions. Finally, our barrier device is expected to elucidate mechanisms of drug transport at the BBB. The large membrane interface combined with the low channel volumes allow an easy detection of compounds. Here, the barrier selectivity for the LY paracellular marker was reported as an example to confirm the feasibility of permeability studies in these channels. The plate format offers the possibility to use six replicates simultaneously in the same environment, or to create different individual experimental conditions in parallel. Finally, the cost of our barrier device is affordable as it represents less than six euros per condition.

Limitations and future works:

Some points still deserve further investigations to achieve a complete characterization of this model. Firstly, the device configuration offers the possibility to incorporate other cell types in the lower compartment for a more physiologically relevant model. Co-culture induces cell-cell interactions for further BMEC differentiation towards a BBB phenotype [58]. Among the cellular components of the BBB, glial cells are known to particularly improve the function and regulation of $\operatorname{BMEC}[59,60]$. However, in hCMEC/D3 cells specifically, improvement of $\mathrm{BBB}$ properties in response to astrocytes was controversial since two studies reported no changes in endothelial cell function [43,61]. For this reason, and to firstly develop a simple model, we preferred to validate our device with a monoculture. However, in future works, it could be interesting to test this configuration to rule on the co-culture impact on hCMEC/D3 cells in combination with shear stress.

Analysis of cell orientation was performed to validate the effective shear stress exposure. Nitric oxide is another indicator that could also be used. This key intercellular messenger of mechano-transduction is produced by BMEC under shear stress exposure and exerts neuroprotective and anti-inflammatory effects [62-64]. It could be interesting to 
monitor the NO release in both upper and lower compartments during shear stress exposure.

To characterize endothelial cell differentiation, other BBB markers are relevant as VEcadherin and PECAM-1 adherent junctions which are well-expressed in hCMEC/D3 cells.

We demonstrated the feasibility of permeability measurement in our device by investigating the paracellular transport of LY. However, various tracers with different molecular weights are necessary to attest to the restrictive barrier function. The transcellular route could also be explored, for example, by using FITC-transferrin to evaluate the transcytosis or P-glycoprotein substrates with or without a specific inhibitor for measuring active efflux transport. Moreover, it could be more physiologically relevant to measure the permeability of an analyte under perfusion, by recirculating the incubation solution with a steady flow rate and collecting samples gradually from the abluminal compartment [54]. The advantage is that the concentrations of analyte are kept constant during incubation in both compartments.

\section{Conclusions}

Our data show that our barrier device is suitable for the culture of BMEC for at least seven days under shear stress exposure, and reproduces some BBB features. It is expected to elucidate transport mechanisms for existing pharmaceutical compounds or drug candidates, as well as to study new therapeutic modalities or targets at the BBB.

Our next challenge is the implementation of built-in electrodes in order to monitor the trans-endothelial electrical resistance directly in the incubator during the culture. This functionality allows to non-invasively and instantly determine when the cell differentiation is optimal to perform pharmacokinetic studies. Our home-made device opens the way to other organ representations, as all cell barrier models can be modelized in this configuration, including kidney or intestinal epithelial barriers, for example.

Supplementary Materials: The following are available online at https:/ /www.mdpi.com/article/10 .3390/app11125584/s1, Supplementary Data S1: Device manufacturing procedure, Supplementary Data S2: Flow rate calculations, Supplementary Data S3: Cell orientation analysis.

Author Contributions: Conceptualization, N.C. and A.R.; methodology, J.L. and L.G.B.; investigation, Y.M., C.d.R. and N.C.; formal analysis, N.C. and Y.M.; validation, N.C.; visualization, L.G.B., N.C.; writing—original draft preparation, N.C.; writing—review and editing, C.d.R., A.R. and X.D.; supervision, X.D. and A.R.; funding acquisition, N.C., X.D. and A.R., X.D. and A.R. are co-last authors, they contributed equally to this work. All authors have read and agreed to the published version of the manuscript.

Funding: This work was financially supported by Servier, HEPIA HES-SO, and SCAHT.

Acknowledgments: The authors would like to thank Pierre-Olivier Couraud and Sandrine Bourdoulous for the hCMEC/D3 cell donation and for helpful discussions. We also thank Laetitia Nikles for technical support and cell culture, Luc Stoppini for critical input, and Valérie Dias for English revision. The authors acknowledge the Cell and Tissue Imaging (PICT-IBiSA), Institut Curie, member of the French National Research Infrastructure France-BioImaging (ANR10-INBS-04), and particularly Vincent Fraisier and Anne-Sophie Mace for their expert technical help. The authors greatly thank Technologie Servier for granting funding, and particularly Claire Denizot and Yannick Parmentier for their support.

Conflicts of Interest: The authors declare no conflict of interest.

\section{References}

1. Feigin, V.L.; Nichols, E.; Alam, T.; Bannick, M.S.; Beghi, E.; Blake, N.; Culpepper, W.J.; Dorsey, E.R.; Elbaz, A.; Ellenbogen, R.G.; et al. Global, Regional, and National Burden of Neurological Disorders, 1990-2016: A Systematic Analysis for the Global Burden of Disease Study 2016. Lancet Neurol. 2019, 18, 459-480. [CrossRef]

2. Di Luca, M.; Baker, M.; Corradetti, R.; Kettenmann, H.; Mendlewicz, J.; Olesen, J.; Ragan, I.; Westphal, M. Consensus Document on European Brain Research. Eur. J. Neurosci. 2011, 33, 768-818. [CrossRef] 
3. Pangalos, M.N.; Schechter, L.E.; Hurko, O. Drug Development for CNS Disorders: Strategies for Balancing Risk and Reducing Attrition. Nat. Rev. Drug Discov. 2007, 6, 521-532. [CrossRef]

4. Hay, M.; Thomas, D.W.; Craighead, J.L.; Economides, C.; Rosenthal, J. Clinical Development Success Rates for Investigational Drugs. Nat. Biotechnol. 2014, 32. [CrossRef]

5. Zhou, S.; Johnson, R. Pharmaceutical Probability of Success; Alacrita: London, UK, 2019.

6. Henderson, J.T.; Piquette-Miller, M. Blood-Brain Barrier: An Impediment to Neuropharmaceuticals. Clin. Pharmacol. Ther. 2015, 97, 308-313. [CrossRef] [PubMed]

7. Rahman, N.A.; Rasil, A.N.H.M.; Meyding-Lamade, U.; Craemer, E.M.; Diah, S.; Tuah, A.A.; Muharram, S.H. Immortalized Endothelial Cell Lines for in Vitro Blood-Brain Barrier Models: A Systematic Review. Brain Res. 2016, 1642, 532-545. [CrossRef]

8. Davies, P.F. Flow-Mediated Endothelial Mechanotransduction. Physiol. Rev. 1995, 75, 519-560. [CrossRef]

9. Akimoto, S.; Mitsumata, M.; Sasaguri, T.; Yoshida, Y. Laminar Shear Stress Inhibits Vascular Endothelial Cell Proliferation by Inducing Cyclin-Dependent Kinase Inhibitor P21 Sdi1/Cip1/Waf1. Circ. Res. 2000, 86, 185-190. [CrossRef]

10. Garcia-Polite, F.; Martorell, J.; del Rey-Puech, P.; Melgar-Lesmes, P.; O’Brien, C.C.; Roquer, J.; Ois, A.; Principe, A.; Edelman, E.R.; Balcells, M. Pulsatility and High Shear Stress Deteriorate Barrier Phenotype in Brain Microvascular Endothelium. J. Cereb. Blood Flow Metab. 2017, 37, 2614-2625. [CrossRef] [PubMed]

11. Wang, X.; Xu, B.; Xiang, M.; Yang, X.; Liu, Y.; Liu, X.; Shen, Y. Advances on Fluid Shear Stress Regulating Blood-Brain Barrier. Microvasc. Res. 2020, 128, 103930. [CrossRef] [PubMed]

12. Koutsiaris, A.G.; Tachmitzi, S.V.; Batis, N.; Kotoula, M.G.; Karabatsas, C.H.; Tsironi, E.; Chatzoulis, D.Z. Volume Flow and Wall Shear Stress Quantification in the Human Conjunctival Capillaries and Post-Capillary Venules In Vivo. Biorheology 2007, 44, 375-386. [PubMed]

13. Wong, A.D.; Ye, M.; Levy, A.F.; Rothstein, J.D.; Bergles, D.E.; Searson, P.C. The Blood-Brain Barrier: An Engineering Perspective. Front. Neuroeng. 2013, 6, 7. [CrossRef] [PubMed]

14. Mairey, E.; Genovesio, A.; Donnadieu, E.; Bernard, C.; Jaubert, F.; Pinard, E.; Seylaz, J.; Olivo-Marin, J.-C.; Nassif, X.; Duménil, G. Cerebral Microcirculation Shear Stress Levels Determine Neisseria Meningitidis Attachment Sites along the Blood-Brain Barrier. J. Exp. Med. 2006, 203, 1939-1950. [CrossRef] [PubMed]

15. Weksler, B.; Romero, I.A.; Couraud, P.-O. The HCMEC/D3 Cell Line as a Model of the Human Blood Brain Barrier. Fluids Barriers CNS 2013, 10, 16. [CrossRef] [PubMed]

16. Dauchy, S.; Miller, F.; Couraud, P.-O.; Weaver, R.J.; Weksler, B.; Romero, I.-A.; Scherrmann, J.-M.; de Waziers, I.; Declèves, X. Expression and Transcriptional Regulation of ABC Transporters and Cytochromes P450 in HCMEC/D3 Human Cerebral Microvascular Endothelial Cells. Biochem. Pharmacol. 2009, 77, 897-909. [CrossRef]

17. Cecchelli, R.; Dehouck, B.; Descamps, L.; Fenart, L.; Buée-Scherrer, V.; Duhem, C.; Lundquist, S.; Rentfel, M.; Torpier, G.; Dehouck, M.P. In Vitro Model for Evaluating Drug Transport across the Blood-Brain Barrier. Adv. Drug Deliv. Rev. 1999, 36, 165-178. [CrossRef]

18. Zhao, W.; Han, L.; Bae, Y.; Manickam, D.S. Lucifer Yellow-A Robust Paracellular Permeability Marker in a Cell Model of the Human Blood-Brain Barrier. J. Vis. Exp. 2019, e58900. [CrossRef]

19. Wu, W.I.; Rezai, P.; Hsu, H.H.; Selvaganapathy, P.R. Materials and methods for the microfabrication of microfluidic biomedical devices. In Microfluidic Devices for Biomedical Applications; Elsevier: Amsterdam, The Netherlands, 2013.

20. Matellan, C.; del Río Hernández, A.E. Cost-Effective Rapid Prototyping and Assembly of Poly(Methyl Methacrylate) Microfluidic Devices. Sci. Rep. 2018, 8, 6971. [CrossRef]

21. Eigenmann, D.E.; Xue, G.; Kim, K.S.; Moses, A.V.; Hamburger, M.; Oufir, M. Comparative Study of Four Immortalized Human Brain Capillary Endothelial Cell Lines, HCMEC/D3, HBMEC, TY10, and BB19, and Optimization of Culture Conditions, for an in Vitro Blood-Brain Barrier Model for Drug Permeability Studies. Fluids Barriers CNS 2013, 10, 33. [CrossRef]

22. Chung, B.J.; Robertson, A.M.; Peters, D.G. The Numerical Design of a Parallel Plate Flow Chamber for Investigation of Endothelial Cell Response to Shear Stress. Comput. Struct. 2003, 81, 535-546. [CrossRef]

23. Son, Y. Determination of Shear Viscosity and Shear Rate from Pressure Drop and Flow Rate Relationship in a Rectangular Channel. Polymer 2007, 48, 632-637. [CrossRef]

24. Young, E.W.K.; Beebe, D.J. Fundamentals of Microfluidic Cell Culture in Controlled Microenvironments. Chem. Soc. Rev. 2010, 39, 1036-1048. [CrossRef] [PubMed]

25. Bakker, D.P.; van der Plaats, A.; Verkerke, G.J.; Busscher, H.J.; van der Mei, H.C. Comparison of Velocity Profiles for Different Flow Chamber Designs Used in Studies of Microbial Adhesion to Surfaces. Appl. Environ. Microbiol. 2003, 69, 6280-6287. [CrossRef]

26. Papaioannou, T.G.; Stefanadis, C. Vascular Wall Shear Stress: Basic Principles and Methods. Hell. J. Cardiol. 2005, 46, 9-15.

27. Cornish, R.J. Flow in a Pipe of Rectangular Cross-Section. Proc. R. Soc. Lond. Ser. A Math. Phys. Sci. 1928, 120, 691-700.

28. Cornford, E.M.; Hyman, S.; Cornford, M.E.; Landaw, E.M.; Delgado-Escueta, A.V. Interictal Seizure Resections Show Two Configurations of Endothelial Glut1 Glucose Transporter in the Human Blood-Brain Barrier. J. Cereb. Blood Flow Metab. 1998, 18, 26-42. [CrossRef]

29. McCormick, S.M.; Seil, J.T.; Smith, D.S.; Tan, F.; Loth, F. Transitional Flow in a Cylindrical Flow Chamber for Studies at the Cellular Level. Cardiovasc. Eng. Technol. 2012, 3, 439-449. [CrossRef] 
30. Shao, X.; Gao, D.; Chen, Y.; Jin, F.; Hu, G.; Jiang, Y.; Liu, H. Development of a Blood-Brain Barrier Model in a Membrane-Based Microchip for Characterization of Drug Permeability and Cytotoxicity for Drug Screening. Anal. Chim. Acta 2016, 934, 186-193. [CrossRef]

31. Zakharova, M.; Palma do Carmo, M.A.; van der Helm, M.W.; Le-The, H.; de Graaf, M.N.S.; Orlova, V.; van den Berg, A.; van der Meer, A.D.; Broersen, K.; Segerink, L.I. Multiplexed Blood-Brain Barrier Organ-on-Chip. Lab Chip 2020, 20, 3132-3143. [CrossRef]

32. Sellgren, K.L.; Hawkins, B.T.; Grego, S. An Optically Transparent Membrane Supports Shear Stress Studies in a Three-Dimensional Microfluidic Neurovascular Unit Model. Biomicrofluidics 2015, 9, 061102. [CrossRef]

33. Maoz, B.M.; Herland, A.; FitzGerald, E.A.; Grevesse, T.; Vidoudez, C.; Pacheco, A.R.; Sheehy, S.P.; Park, T.-E.; Dauth, S.; Mannix, R.; et al. A Linked Organ-on-Chip Model of the Human Neurovascular Unit Reveals the Metabolic Coupling of Endothelial and Neuronal Cells. Nat. Biotechnol. 2018, 36, 865-874. [CrossRef] [PubMed]

34. Griep, L.M.; Wolbers, F.; de Wagenaar, B.; ter Braak, P.M.; Weksler, B.B.; Romero, I.A.; Couraud, P.O.; Vermes, I.; van der Meer, A.D.; van den Berg, A. BBB on CHIP: Microfluidic Platform to Mechanically and Biochemically Modulate Blood-Brain Barrier Function. Biomed. Microdevices 2013, 15, 145-150. [CrossRef]

35. Ahn, S.I.; Sei, Y.J.; Park, H.-J.; Kim, J.; Ryu, Y.; Choi, J.J.; Sung, H.-J.; MacDonald, T.J.; Levey, A.I.; Kim, Y. Microengineered Human Blood-Brain Barrier Platform for Understanding Nanoparticle Transport Mechanisms. Nat. Commun. 2020, 11, 175. [CrossRef]

36. Xu, H.; Li, Z.; Yu, Y.; Sizdahkhani, S.; Ho, W.S.; Yin, F.; Wang, L.; Zhu, G.; Zhang, M.; Jiang, L.; et al. A Dynamic in Vivo-like Organotypic Blood-Brain Barrier Model to Probe Metastatic Brain Tumors. Sci. Rep. 2016, 6, 36670. [CrossRef]

37. Park, T.-E.; Mustafaoglu, N.; Herland, A.; Hasselkus, R.; Mannix, R.; FitzGerald, E.A.; Prantil-Baun, R.; Watters, A.; Henry, O.; Benz, M.; et al. Hypoxia-Enhanced Blood-Brain Barrier Chip Recapitulates Human Barrier Function and Shuttling of Drugs and Antibodies. Nat. Commun. 2019, 10, 2621. [CrossRef] [PubMed]

38. Walter, F.R.; Valkai, S.; Kincses, A.; Petneházi, A.; Czeller, T.; Veszelka, S.; Ormos, P.; Deli, M.A.; Dér, A. A Versatile Lab-on-a-Chip Tool for Modeling Biological Barriers. Sens. Actuators B Chem. 2016, 222, 1209-1219. [CrossRef]

39. Adriani, G.; Ma, D.; Pavesi, A.; Kamm, R.D.; Goh, E.L.K. A 3D Neurovascular Microfluidic Model Consisting of Neurons, Astrocytes and Cerebral Endothelial Cells as a Blood-Brain Barrier. Lab Chip 2017, 17, 448-459. [CrossRef] [PubMed]

40. Brown, T.D.; Nowak, M.; Bayles, A.V.; Prabhakarpandian, B.; Karande, P.; Lahann, J.; Helgeson, M.E.; Mitragotri, S. A Microfluidic Model of Human Brain (MHuB) for Assessment of Blood Brain Barrier. Bioeng. Transl. Med. 2019, 4, e10126. [CrossRef]

41. Wong, A.K.; LLanos, P.; Boroda, N.; Rosenberg, S.R.; Rabbany, S.Y. A Parallel-Plate Flow Chamber for Mechanical Characterization of Endothelial Cells Exposed to Laminar Shear Stress. Cell. Mol. Bioeng. 2016, 9, 127-138. [CrossRef]

42. Moya, M.; Triplett, M.; Simon, M.; Alvarado, J.; Booth, R.; Osburn, J.; Soscia, D.; Qian, F.; Fischer, N.; Kulp, K.; et al. A Reconfigurable in Vitro Model for Studying the Blood Brain Barrier. Ann. Biomed. Eng. 2019, 48, 780-793. [CrossRef]

43. Weksler, B.B.; Subileau, E.A.; Perrière, N.; Charneau, P.; Holloway, K.; Leveque, M.; Tricoire-Leignel, H.; Nicotra, A.; Bourdoulous, S.; Turowski, P.; et al. Blood-brain Barrier-specific Properties of a Human Adult Brain Endothelial Cell Line. FASEB J. 2005, 19, 1872-1874. [CrossRef] [PubMed]

44. Urich, E.; Lazic, S.E.; Molnos, J.; Wells, I.; Freskgård, P.O. Transcriptional Profiling of Human Brain Endothelial Cells Reveals Key Properties Crucial for Predictive in Vitro Blood-Brain Barrier Models. PLoS ONE 2012, 7, e38149. [CrossRef] [PubMed]

45. Liebner, S.; Corada, M.; Bangsow, T.; Babbage, J.; Taddei, A.; Czupalla, C.J.; Reis, M.; Felici, A.; Wolburg, H.; Fruttiger, M.; et al. Wnt/ $\beta$-Catenin Signaling Controls Development of the Blood-Brain Barrier. J. Cell Biol. 2008, 183, 409-417. [CrossRef] [PubMed]

46. Laksitorini, M.D.; Yathindranath, V.; Xiong, W.; Hombach-Klonisch, S.; Miller, D.W. Modulation of Wnt/ $\beta$-Catenin Signaling Promotes Blood-Brain Barrier Phenotype in Cultured Brain Endothelial Cells. Sci. Rep. 2019, 9, 19718. [CrossRef]

47. Reinitz, A.; DeStefano, J.; Ye, M.; Wong, A.D.; Searson, P.C. Human Brain Microvascular Endothelial Cells Resist Elongation Due to Shear Stress. Microvasc. Res. 2015, 99, 8-18. [CrossRef]

48. Jiang, L.; Li, S.; Zheng, J.; Li, Y.; Huang, H. Recent Progress in Microfluidic Models of the Blood-Brain Barrier. Micromachines 2019, 10, 375. [CrossRef]

49. Elbakary, B.; Badhan, R.K.S. A Dynamic Perfusion Based Blood-Brain Barrier Model for Cytotoxicity Testing and Drug Permeation. Sci. Rep. 2020, 10, 3788. [CrossRef]

50. Edington, C.D.; Chen, W.L.K.; Geishecker, E.; Kassis, T.; Soenksen, L.R.; Bhushan, B.M.; Freake, D.; Kirschner, J.; Maass, C.; Tsamandouras, N.; et al. Interconnected Microphysiological Systems for Quantitative Biology and Pharmacology Studies. Sci. Rep. 2018, 8, 3788. [CrossRef]

51. Davies, A.E.; Williams, R.L.; Lugano, G.; Pop, S.R.; Kearns, V.R. In Vitro and Computational Modelling of Drug Delivery across the Outer Blood-Retinal Barrier. Interface Focus 2020, 10, 20190132. [CrossRef] [PubMed]

52. Wevers, N.R.; Kasi, D.G.; Gray, T.; Wilschut, K.J.; Smith, B.; Vught, R.; Shimizu, F.; Sano, Y.; Kanda, T.; Marsh, G.; et al. A Perfused Human Blood-Brain Barrier on-a-Chip for High-Throughput Assessment of Barrier Function and Antibody Transport. Fluids Barriers CNS 2018, 15, 23. [CrossRef]

53. Bang, S.; Lee, S.-R.; Ko, J.; Son, K.; Tahk, D.; Ahn, J.; Im, C.; Jeon, N.L. A Low Permeability Microfluidic Blood-Brain Barrier Platform with Direct Contact between Perfusable Vascular Network and Astrocytes. Sci. Rep. 2017, 7, 8083. [CrossRef] [PubMed]

54. Booth, R.; Kim, H. Permeability Analysis of Neuroactive Drugs Through a Dynamic Microfluidic In Vitro Blood-Brain Barrier Model. Ann. Biomed. Eng. 2014, 42, 2379-2391. [CrossRef]

55. Wang, Y.I.; Abaci, H.E.; Shuler, M.L. Microfluidic Blood-Brain Barrier Model Provides In Vivo-Like Barrier Properties for Drug Permeability Screening. Biotechnol. Bioeng 2017, 114, 184-194. [CrossRef] 
56. Van der Helm, M.W.; van der Meer, A.D.; Eijkel, J.C.T.; van den Berg, A.; Segerink, L.I. Microfluidic Organ-on-Chip Technology for Blood-Brain Barrier Research. Tissue Barriers 2016, 4, e1142493. [CrossRef] [PubMed]

57. Deosarkar, S.P.; Prabhakarpandian, B.; Wang, B.; Sheffield, J.B.; Krynska, B.; Kiani, M.F. A Novel Dynamic Neonatal Blood-Brain Barrier on a Chip. PLoS ONE 2015, 10, e0142725. [CrossRef]

58. Obermeier, B.; Daneman, R.; Ransohoff, R.M. Development, Maintenance and Disruption of the Blood-Brain Barrier. Nat. Med. 2013, 19, e0142725. [CrossRef]

59. Pekny, M.; Stanness, K.A.; Eliasson, C.; Betsholtz, C.; Janigro, D. Impaired Induction of Blood-Brain Barrier Properties in Aortic Endothelial Cells by Astrocytes from GFAB-Deficient Mice. Glia 1998, 22, 390-400. [CrossRef]

60. Abbott, N.J.; Rönnbäck, L.; Hansson, E. Astrocyte-Endothelial Interactions at the Blood-Brain Barrier. Nat. Rev. Neurosci. 2006, 7, 41-53. [CrossRef]

61. Cucullo, L.; Couraud, P.-O.; Weksler, B.; Romero, I.-A.; Hossain, M.; Rapp, E.; Janigro, D. Immortalized Human Brain Endothelial Cells and Flow-Based Vascular Modeling: A Marriage of Convenience for Rational Neurovascular Studies. J. Cereb. Blood Flow Metab. 2008, 28, 312-328. [CrossRef] [PubMed]

62. Janigro, D.; West, G.A.; Nguyen, T.S.; Winn, H.R. Regulation of Blood-Brain Barrier Endothelial Cells by Nitric Oxide. Circ. Res. 1994, 75, 528-538. [CrossRef]

63. Thiel, V.E.; Audus, K.L. Nitric Oxide and Blood-Brain Barrier Integrity. Antioxid. Redox Signal. 2001, 3, 273-278. [CrossRef] [PubMed]

64. Olivera, G.C.; Ren, X.; Vodnala, S.K.; Lu, J.; Coppo, L.; Leepiyasakulchai, C.; Holmgren, A.; Kristensson, K.; Rottenberg, M.E. Nitric Oxide Protects against Infection-Induced Neuroinflammation by Preserving the Stability of the Blood-Brain Barrier. PLoS Pathog. 2016, 12, e1005442. [CrossRef] [PubMed] 